\title{
IMPACTOS DA PANDEMIA DE COVID-19 NO LAZER E NO TRABALHO DO PROFESSOR UNIVERSITÁRIO EM HOME OFFICE
}

Recebido em: 17/03/2021

Aprovado em: 19/07/2021

Licença:@® @ @

Vagner Miranda da Conceição ${ }^{1}$

Faculdade Pitágoras

Betim/Contagem - MG - Brasil

RESUMO: A pandemia de COVID-19 trouxe novas formas de ser e estar, impactando no lazer e no trabalho do professor universitário em home office. Analisar os impactos da pandemia de COVID-19 nessas dimensões foi o foco dessa pesquisa. A coleta com 44 professores via Google Forms foi analisada via análise de conteúdo e estatística descritiva. Dados sobre perfil socioeconômico, tempo e demanda de trabalho, tempo de e satisfação com o lazer, atividades de lazer antes e durante a pandemia, lazer que sente falta e lazer novo e importância e necessidade do lazer durante a pandemia revelam que, no contexto de pandemia, refletir sobre o lazer do professor, que foi limitado, transformado e suprimido pela rápida adaptação ao trabalho remoto e pelo entrelaçar dos tempos de lazer e trabalho no ambiente doméstico, é urgente e necessário.

PALAVRAS-CHAVE: Atividades de Lazer. Professor Universitário. COVID-19.

\section{IMPACTS OF THE COVID-19 PANDEMIC ON LEISURE AND UNIVERSITY TEACHER'S WORK IN HOME OFFICE}

ABSTRACT: The COVID-19 pandemic brought new ways of being, impacting the leisure and the work of the university professor in home office. Analyzing the impacts of the COVID-19 pandemic in these dimensions was the aim of this study. The collection with 44 professor's via Google Forms was analyzed via content analysis and descriptive statistics. Data on socioeconomic profile, time and demand for work, time spent and satisfaction with leisure, leisure activities before and during the pandemic, missing leisure and new leisure and the importance and need for leisure during the pandemic reveal that, in the context of pandemic, reflecting on the professor's leisure, which has been limited, transformed and suppressed by the rapid adaptation to remote work and by the interweaving of leisure and work times in the domestic environment, is urgent and necessary.

KEYWORDS: Leisure Activities. University Professor. Coronavirus Infections.

\footnotetext{
${ }^{1}$ Doutor em Estudos do Lazer (UFMG). Docente na Faculdade Pitágoras - Betim e Contagem (MG).
} 
Impactos da Pandemia de COVID-19 no Lazer e no Trabalho do Professor Universitário em Home Office

Vagner Miranda da Conceição

\section{Introdução}

Na medicina, pandemia expressa a ampla e simultânea disseminação geográfica de uma doença. Historicamente, a população mundial já (sobre) viveu a algumas pandemias, que foram propulsoras de fortes transformações sociais e incentivaram o desenvolvimento e a valorização da Ciência (COUTO; REZENDE; MEDINA, 2020), e que, devido às milhares de vidas perdidas, deixaram marcas que não devem ser esquecidas.

Desde março de 2020, a população brasileira está exposta a pandemia de uma doença infecciosa causada por um novo coronavírus (SARS-CoV-2) descoberto pela Organização Mundial da Saúde (OMS) em dezembro de 2019, após vários casos de pneumonia viral na cidade de Wuhan, China (WHO, 2021). Atualmente e popularmente conhecido como COVID-19, esse vírus ultrapassou as fronteiras chinesas e se espalhou pelo mundo, demonstrando o seu rápido poder de contaminação. Após acometer várias pessoas no mundo inteiro e causando óbitos exponenciais diários, a OMS, em 11 de março de 2020, confirma que o mundo estava por uma pandemia de COVID-19 (OPAS, 2020), fato esse que tem obrigado a população mundial a refletir e a ressignificar alguns comportamentos sociais.

Após um ano do alarme mundial acerca da pandemia de COVID-19, somam-se, atualmente $^{2}$, 2.656.822 mortes no mundo inteiro e 278.229 mortes no Brasil (WHO, 2021). Para evitar tal extremo e um possível colapso nos sistemas de saúde, a WHO (2021) recomenda que alguns comportamentos, baseados em hábitos de higiene e protocolos sanitários, devem ser (re) inseridos no cotidiano de toda a população.

O distanciamento social é um conjunto de medidas que objetivam reduzir a quantidade de pessoas circulantes para evitar uma possível infecção pelo COVID-19

\footnotetext{
${ }^{2}$ Dados extraídos em 16/03/2021.
} 
Impactos da Pandemia de COVID-19 no Lazer e no Trabalho do Professor Universitário em Home Office

Vagner Miranda da Conceição

(WHO, 2021). O objetivo é conter aglomerações podendo, em alguns casos, ser necessário a paralisação de atividades não essenciais, escolares e a adoção do sistema de trabalho remoto (GOMES; ARAÚJO, 2020). O isolamento social, medida mais rígida, objetiva o déficit na frequência de contato com amigos, familiares e sociedade como um todo, permitindo somente o deslocamento para consumo de serviços essenciais: alimentação, medicamentos, atendimento médico etc. (ESCALANTE; GOLDEN; MASON, 2021).

A adoção de novos comportamentos via adaptação à nova rotina diária, para além das dimensões de autocuidado, é uma estratégia que reverbera nos contextos socioeconômicos, religiosos, educacionais, laborais, de lazer etc. Diversas funções laborais tiveram que ser adaptadas ao "novo normal", assim como, experiências e possibilidades de lazer passaram por uma reestruturação e ressignificação para esse momento. (In) Diretamente, toda a população tem sido atingida e forçada a repensar e a reelaborar seus comportamentos, atitudes e funções sociais.

No contexto de trabalho, algumas funções e atividades laborais, dependendo do momento da pandemia, sofreram restrições no seu desenvolvimento, sendo paralisadas ou adaptadas a esse novo contexto. Uma das adaptações possíveis e recorrente nesse momento é o desempenho das funções via home office, que a execução do trabalho em casa, utilizando tecnologias de informação e comunicação (internet, computador, celular etc.) (LOSEKANN; MOURÃO, 2020).

Um dos profissionais que tem atuado em casa é o professor universitário, que no caso das instituições que não paralisaram as suas atividades, tem se desdobrado para executar e manter a tarefa do ensino. Independente das condições do alunado e do professorado para acompanhar esse processo, pois existem complicadores, o ensino presencial se adaptou em ensino remoto. A falta de acesso à internet de qualidade, 
Impactos da Pandemia de COVID-19 no Lazer e no Trabalho do Professor Universitário em Home Office

Vagner Miranda da Conceição

impossibilidade de usar um computador ou celular para acompanhar as transmissões, condições pessoais para acompanhar ou executar uma aula no estilo remoto, incertezas sobre a real efetivação desse processo de ensino, que de forma urgente foi transformado, muitas vezes não permitindo um aprendizado e domínio de qualidade das ferramentas utilizadas, são exemplos de dificultadores que podem comprometer o ensino.

O professor sofreu algumas pressões (aprender sobre as plataformas utilizadas, adaptar seus conteúdos presenciais para o sistema remoto, reestruturar o seu ensino para o contato com os alunos por uma tela etc.) para que o seu trabalho pudesse ser desempenhado, garantindo ao aluno o acesso aos conteúdos, durante o horário de aula. No entanto, o trabalho docente não se restringe ao tempo/momento de aula, em especial o professor universitário que, para além do ensino, pode atuar na pesquisa e na extensão.

Para a produção de uma aula, muitas horas são despendidas em pesquisa, leitura, organização e produção do material e isso é realizado fora do tempo de trabalho, do horário de aula. Nesse contexto, o tempo de lazer pode ser comprometido, já que o lazer é vivenciado no tempo disponível das não obrigações (MARCELLINO, 2010). Durante a pandemia, os modos de morar e trabalhar se entrelaçaram num mesmo espaço que também é o de estudar, exercitar, descansar, distrair etc. (FALCÃO; GOMES, 2020; MATOS; PINHEIRO; BAHIA, 2020; MAYOR; SILVA; LOPES, 2020), unindo espaço público-particular, repouso-trabalho-divertimento e tempo de trabalho e tempo de lazer (CASTILHO; RIBEIRO; UNGHERI, 2020; LOSEKANN; MOURÃO, 2020).

O lazer, direito social, é uma conquista do povo e efetiva-se, dentre as suas outras características, na possibilidade de fazer escolhas entre as diversas práticas de lazer, que atualmente estão em constante processo de des-,re- e construção (CLEMENTE; STOPPA, 2020; FALCÃO; GOMES, 2020). A liberdade de escolha, que 
Impactos da Pandemia de COVID-19 no Lazer e no Trabalho do Professor Universitário em Home Office

Vagner Miranda da Conceição

caracteriza o protagonismo no lazer, foi afetada, pois em contexto de isolamento social as opções foram reduzidas aos espaços ambiente aberto sem aglomerações e domiciliar (COUTO; REZENDE; MEDINA, 2020; SILVA et al., 2020), num tempo que passa a abarcar todas as atividades diárias.

Essa nova organização compromete a experiência de lazer devido ao surgimento de novas obrigações domésticas e sociofamiliares (CASTILHO; RIBEIRO; UNGHERI, 2020). A presença de outras pessoas dividindo o espaço casa, muitas vezes com os mesmos horários de trabalho e/ou utilizando os mesmos equipamentos tanto para o trabalho quanto para o lazer podem comprometer a relação do sujeito com o tempo. Castilho; Ribeiro e Ungheri (2020) ressaltam que a presença de idosos e crianças em casa demandam, nesse momento, uma organização especial, pois o primeiro enseja muito cuidado e atenção, pois é considerado grupo de risco e o segundo, pelas necessidades sociais e de divertimento, que transformam a dinâmica de convívio e espacial. Lins et al. (2020) reforçam um cuidado especial com o idoso, pois a quarentena pode representar sentimentos e emoções negativas: angústia, solidão, tristeza etc.

Dumazedier (1980) apresenta uma classificação, não estanque, para as atividades de lazer, entendendo o conjunto de práticas como interesses culturais: físico-esportivos, artísticos, manuais, intelectuais e sociais. Com o dinamismo e necessidade da Ciência para organizar e classificar as práticas, dois interesses foram acrescidos: turísticos, de Camargo (1992); e virtuais, de Schwartz (2003). Esses arranjos não são fechados e as atividades de lazer podem permear ora um interesse, ora outro.

Alguns trabalhos sobre os impactos da pandemia de COVID-19 no lazer ou em dimensões inerentes a essa dimensão da vida foram publicados recentemente. Produções iniciais, pois ainda estamos em processo de pandemia já abordaram o estudante 
Impactos da Pandemia de COVID-19 no Lazer e no Trabalho do Professor Universitário em Home Office

Vagner Miranda da Conceição

universitário (MATOS; PINHEIRO; BAHIA， 2020; CASTILHO; RIBEIRO; UNGHERI, 2020; MONTENEGRO; QUEIROZ; DIAS, 2020), as mulheres (MAYOR; SILVA; LOPES, 2020), os adultos e idosos (LINS et al., 2020; RIBEIRO et al., 2020), o home office (LOSEKANN; MOURÃO, 2020), espaço doméstico (CLEMENTE; STOPPA, 2020); aplicativos de smartphone (CAVALCANTE, 2020). No entanto, em contexto brasileiro, não foram encontradas publicações que elucidassem os impactos da pandemia de COVID-19 no lazer do professor universitário.

Se antes da pandemia, o trabalho do professor universitário já possuía demandas e reflexões sobre o tempo disponível das obrigações e sobre o lazer, agora, em tempo de distanciamento social, parece que o envolvimento em atividades de lazer, para além dos danos oriundos da pandemia, tem sido afetado também pelas condições de trabalho. A relação dialética lazer-trabalho (DUMAZEDIER, 1980; MARCELLINO, 2007), centro de várias publicações, no contexto atual merece espaço para ampliar a compreensão dessa aproximação, pois com o home office, a conexão com o trabalho é praticamente em tempo integral, comprometendo e exigindo uma reorganização do tempo de vida (CLEMENTE; STOPPA, 2020; LOSEKANN; MOURÃO, 2020).

Sabe-se que tal complicador não é exclusivo do professor universitário, mas é importante compreender como esse "novo normal" de isolamento social tem repercutido e influenciado na assimilação e vivência do lazer, em especial, a partir da compreensão dessa necessidade humana como direito social que se relaciona com outras dimensões da vida e que pode amenizar o confinamento atual. Nesse caminho, surgem algumas questões: A pandemia tem influenciado no lazer do professor universitário? Como os tempos de lazer e trabalho tem se relacionado durante a pandemia? As atividades de lazer, antes e durante a pandemia, foram impactadas pelo distanciamento social? Partindo desses apontamentos e reflexões, o objetivo desse texto é analisar os impactos 
Impactos da Pandemia de COVID-19 no Lazer e no Trabalho do Professor Universitário em Home Office

Vagner Miranda da Conceição

da pandemia de COVID-19 no lazer e no trabalho home office do professor universitário.

\section{Método}

Essa é uma pesquisa exploratória de natureza quali-quantitativa (GONDIM, 2003). Fizeram parte desse estudo 44 professores universitários, que preencheram um questionário online via plataforma Google Forms, com 35 questões abertas e fechadas organizadas por: perfil socioeconômico, tempo e demanda de trabalho, tempo de e satisfação com o lazer, atividades de lazer antes e durante a pandemia, lazer que sente falta e lazer novo e importância e necessidade do lazer durante a pandemia. As questões foram organizadas para auxiliar na compreensão acerca da relação pandemia e lazer do professor universitário, pois atualmente a dialética lazer-trabalho se faz mais evidente.

Os participantes aceitaram participar da pesquisa via "Termo de consentimento livre e esclarecido", que era o primeiro item de resposta do questionário. O critério de inclusão era que fosse professor universitário.

O questionário, construído a partir da adaptação dos instrumentos de coleta de Ribeiro et al. (2020), de Conceição (2018) e de Stoppa e Isayama (2017), passou por um teste piloto com três professores universitários para solucionar possíveis dúvidas relacionadas ao entendimento das questões. Posteriormente, foi compartilhado via redes sociais (Facebook e Whats App) e via e-mail, entre os dias 09 e 27 de maio de 2020, podendo ainda ser replicado para outros professores universitários via "Bola de neve virtual" (COSTA, 2018), o que resulta em uma amostra por conveniência e não representativa da população.

Os dados coletados foram organizados via Microsoft Excel. A interpretação das questões abertas ocorreu via Análise de conteúdo (BARDIN, 2011), com elaboração de 
Impactos da Pandemia de COVID-19 no Lazer e no Trabalho do Professor Universitário em Home Office

Vagner Miranda da Conceição

categorias baseadas em unidades temáticas semelhantes em sentido. Para as questões fechadas, estatística descritiva com análise percentual (CALLEGARI-JACQUES, 2004).Para a interlocução dos dados com a ciência publicada, foram selecionados artigos científicos nas bases de dados BVS e SciELO reportados a partir das palavraschaves atividades de lazer, trabalho, COVID-19, quarentena, docente e professor universitário. Após a eliminação das duplicidades, leitura do título, do resumo e do texto completo, 17 textos foram selecionados. As seguintes categorias são discutidas a seguir: perfil socioeconômico, tempo e demanda de trabalho, tempo e satisfação com o lazer, atividades de lazer antes e durante a pandemia, lazer que falta e lazer novo e importância e necessidade do lazer durante a pandemia.

\section{Resultados e Discussão}

\section{Perfil Socioeconômico}

Conforme a Tabela 1, os dados do questionário revelaram que, entre os professores, $28(63,6 \%)$ são do sexo feminino, $30(68,2 \%)$ tem entre 25 e 44 anos e 32 $(72,7 \%)$ possuem mestrado ou doutorado completo, $34(77,3 \%)$ são de cor branca, 30 $(68,2 \%)$ são casados ou estão em união estável, 31 (70,4\%) são de Minas Gerais e 41 $(93,2 \%)$ moram em áreas urbanas.

Tabela 1:Frequência e Percentual do Perfil Socioeconômico

\begin{tabular}{c|l|c|c}
\hline \multicolumn{1}{c}{ Dado } & Itens & $\mathbf{N}$ & $\mathbf{\%}$ \\
\hline \multirow{4}{*}{ Sexo } & Feminino & 28 & 63,6 \\
\cline { 2 - 4 } & Masculino & 16 & 36,4 \\
\hline \multirow{4}{*}{ Faixa etária } & Entre 25 e 34 anos & 15 & 34,1 \\
\cline { 2 - 4 } & Entre 35 e 44 anos & 15 & 34,1 \\
\cline { 2 - 4 } & Entre 45 e 54 anos & 11 & 25,0 \\
\cline { 2 - 4 } & Entre 55 e 64 anos & 3 & 6,8 \\
\hline \multirow{4}{*}{ Escolaridade } & Graduação completa & 2 & 4,5 \\
\cline { 2 - 4 } & Especialização completa & 7 & 15,9 \\
\cline { 2 - 4 } & Mestrado incompleto ou em andamento; & 3 & 6,8 \\
\cline { 2 - 4 } & Mestrado completo & 11 & 25 \\
\cline { 2 - 4 } & Doutorado incompleto ou em andamento; & 5 & 11,4 \\
\cline { 2 - 4 } & Doutorado completo & 34 & 36,4 \\
\hline \multirow{2}{*}{ Cor } & Branca & 10 & 77,3 \\
\cline { 2 - 4 } & Parda & 22,7 \\
\hline
\end{tabular}


Impactos da Pandemia de COVID-19 no Lazer e no Trabalho do Professor Universitário em Home Office

Vagner Miranda da Conceição

\begin{tabular}{c|l|c|c}
\hline \multirow{4}{*}{ Estado civil } & Solteiro & 11 & 25 \\
\cline { 2 - 4 } & Casado ou estão em união estável & 30 & 68,2 \\
\cline { 2 - 4 } & Separado/divorciado & 3 & 6,8 \\
\hline \multirow{4}{*}{ Unidade federativa } & Minas Gerais & 31 & 70,5 \\
\cline { 2 - 4 } & São Paulo & 6 & 13,6 \\
\cline { 2 - 4 } & Ceará & 1 & 2,3 \\
\cline { 2 - 4 } & Paraná & 1 & 2,3 \\
\cline { 2 - 4 } & Pernambuco & 1 & 2,3 \\
\cline { 2 - 4 } & Rio Grande do Sul & 2,3 \\
\hline \multirow{2}{*}{ Tipologia municipal } & Zona Rural & 3 & 6,8 \\
\cline { 2 - 4 } & Zona Urbana & 41 & 93,2 \\
\hline
\end{tabular}

Fonte: Elaborada pelo autor

A Tabela 2 apresenta os dados sobre habitação, renda mensal e dependentes.

Dentre os professores, $25(56,8 \%)$ moram em casa, $27(61,4 \%)$ dividem a residência mais 2 ou 3 pessoas, $21(47,7 \%)$ recebiam acima de 5 salários-mínimos por mês antes da pandemia, durante a pandemia, $23(52,3 \%)$ respondentes permaneceram com a mesma renda mensal, 9 (20,5\%) participantes possuem 1 dependente e $4(9,1 \%)$ possuem 2 dependentes menores de 18 anos; e 3 (6,8\%) participantes possuem 1 dependente e $2(4,5 \%)$ possuem 2 dependentes com 65 anos ou mais de idade.

Tabela 2:Frequência e Percentual Sobre Moradia, Renda e Dependentes

\begin{tabular}{|c|c|c|c|}
\hline Dado & Itens & $\mathbf{N}$ & $\%$ \\
\hline \multirow{4}{*}{ Tipo de habitação } & Casa & 25 & 56,8 \\
\hline & Apartamento & 13 & 29,5 \\
\hline & Casa ou apartamento em condomínio & 3 & 6,8 \\
\hline & Chácara/sítio/fazenda & 3 & 6,8 \\
\hline \multirow{3}{*}{$\begin{array}{c}\text { Moradia } \\
\text { compartilhada }\end{array}$} & Mora sozinho & 6 & 13,6 \\
\hline & Mora com mais 2 ou 3 pessoas & 27 & 61,4 \\
\hline & Mora com mais 4 ou 5 pessoas & 11 & 25,0 \\
\hline \multirow{4}{*}{$\begin{array}{c}\text { Renda antes da } \\
\text { pandemia }\end{array}$} & Entre 1 e 2 salários & 2 & 4,5 \\
\hline & Entre 2 e 5 salários & 17 & 38,6 \\
\hline & Acima de 5 salários & 21 & 47,7 \\
\hline & Prefiro não dizer & 4 & 9,1 \\
\hline \multirow{3}{*}{$\begin{array}{c}\text { Renda durante a } \\
\text { pandemia }\end{array}$} & Permaneceu a mesma & 23 & 52,3 \\
\hline & Diminuiu & 20 & 45,5 \\
\hline & Prefiro não dizer & 1 & 2,3 \\
\hline \multirow{3}{*}{$\begin{array}{l}\text { Dependentes } \\
<18 \text { anos }\end{array}$} & 1 dependente & 9 & 20,5 \\
\hline & 2 dependentes & 4 & 9,1 \\
\hline & Não possui dependentes nessa faixa etária & 31 & 70,5 \\
\hline \multirow{3}{*}{$\begin{array}{l}\text { Dependentes } \\
>65 \text { anos }\end{array}$} & 1 dependente & 3 & 6,8 \\
\hline & 2 dependentes & 2 & 4,5 \\
\hline & Não possui dependentes nessa faixa etária & 39 & 88,6 \\
\hline
\end{tabular}

Fonte: Elaborada pelo autor

Refletir sobre os dados de perfil da amostra pode trazer indícios de como o lazer se faz presente na vida desses sujeitos durante a pandemia. A saber, quanto maior o 
Impactos da Pandemia de COVID-19 no Lazer e no Trabalho do Professor Universitário em Home Office

Vagner Miranda da Conceição

nível de escolaridade, maiores são as possibilidades em opções de lazer (PEDRÃO; UVINHA, 2017). O acesso à universidade e aos saberes e formações desse espaço estimulam e desenvolvem a autonomia, tanto pela ampliação da compreensão de mundo quanto pelas qualificações para concorrência e entrada no mercado de trabalho, o que pode incorrer numa melhoria das condições financeiras (CASTILHO; RIBEIRO; UNGHERI, 2020), tendendo a diminuir as barreiras econômicas para o lazer (STOPPA; ISAYAMA, 2017). Nem todas as opções de lazer dependem de recurso financeiro, tais como o acesso parques, museus e espaços esportivos públicos, mas essa condição favorece o acesso a diferentes práticas e possibilidades.

Em diálogo com o contexto, o lazer desvela as angústias e as diferenças sociais, podendo contribuir com a manutenção das condições e possibilidades, fortalecendo estereótipos e valores excludentes, consumistas e massificadores ou com a construção de uma sociedade mais justa, humana, inclusiva e voltada à democracia (COUTO; REZENDE; MEDINA, 2020). A pandemia tende a acentuar as desigualdades sociais (FALCÃO; GOMES, 2020; MAYOR; SILVA; LOPES, 2020) trazendo consequências diretamente proporcionais ao nível de escolaridade do trabalhador (FURCERI; LOUNGANI; OSTRY, 2020) podendo afetar negativamente o lazer daqueles mais pobres, que ou continuaram com as atividades laborais para arcar com os gastos ou perderam o emprego, o que compromete a participação e a satisfação no lazer (CLEMENTE, STOPPA, 2020).

Aproximadamente $23 \%$ da amostra se declarou parda e o restante $(77 \%)$ são brancos. Ao pensarmos nas (des) igualdades sociais, em especial, num país que $43,1 \%$ (IBGE, 2010) da população é parda, mesmo com alguns avanços acerca das políticas de cotas e das discussões raciais, percebe-se uma diferença entre os percentuais da amostra e da população brasileira de pardos. A amostra desse trabalho não é estatisticamente 
Impactos da Pandemia de COVID-19 no Lazer e no Trabalho do Professor Universitário em Home Office

Vagner Miranda da Conceição

representativa, mas revela mais uma das desigualdades presentes na nossa sociedade: 0 acesso e à educação. Por outro lado, as mulheres são maioria (68\%) demonstrando que o desejo e luta por emancipação e ocupação de espaços no ensino superior se efetiva como meio para superar problemáticas sociais (CASTILHO; RIBEIRO; UNGHERI, 2020).

No grupo pesquisado, 86,4\% compartilham a casa com no mínimo mais uma pessoa, podendo chegar a até cinco, o que pode influenciar nas percepções e experiências de lazer no espaço da moradia tanto pela relação desses sujeitos entre si e com o espaço (conforto e qualidade da habitação) (BEZERRA et al., 2020) quanto pela forma de lidar com o tempo dentro e fora de casa antes e durante o isolamento social. A pandemia trouxe novas organizações nas relações domésticas forçando o isolamento total para aqueles que moram só e o convívio entre aqueles que dividem o espaço casa (CLEMENTE; STOPPA, 2020). As casas e seus habitantes não foram preparados para a presença diária, constante e conjunta obrigatória, já que essa é uma das principais estratégias para evitar o contágio. A saber, o hábito de despender tempo fora de casa, incluindo deslocamentos e o trabalho em si, foi mais um dos comportamentos diários reestruturado de forma rápida e ágil (CLEMENTE; STOPPA, 2020), pois agora esse tempo é vivido dentro de casa e, em alguns casos, na companhia de outras pessoas, trazendo reflexões e novas formas de estruturar as relações consigo mesmo, com o outro e com as dimensões tempo e espaço.

Sobre habitação e lazer, poucos são os sujeitos com condições favoráveis e satisfatórias para positivar essa relação (MARCELLINO, 2012). No contexto atual, é um privilégio viver numa chácara/sítio/fazenda, recintos espaçosos que permitem o deslocamento e contato com a natureza. Diferentemente, 93,2\% dos professores vivem em casas, apartamentos e os que moram em condomínios de área urbana, tiveram o 
Impactos da Pandemia de COVID-19 no Lazer e no Trabalho do Professor Universitário em Home Office

Vagner Miranda da Conceição

espaço para o lazer reduzido, pois as áreas coletivas foram fechadas para reduzir a circulação das pessoas (CASTILHO; RIBEIRO; UNGHERI, 2020; CLEMENTE; STOPPA, 2020).

\section{Trabalho Home Office: A Demanda e Tempo de Dedicação Aumentaram}

Quanto à situação de trabalho antes e durante a pandemia, 31 (70,5\%) professores permaneceram no mesmo trabalho e desenvolvendo as mesmas atividades, porém de forma remota (home office), em relação ao tempo de trabalho diário em horas durante a pandemia, $17(38,6 \%)$ professores assinalaram entre 8 e 12 horas e $9(20,5)$ acima de 12 horas diárias de trabalho. Para 32(72,3\%) professores a demanda de trabalho aumentou durante a pandemia (TABELA 3).

\section{Tabela 3:Frequência e percentual dos dados laborais}

\begin{tabular}{c|l|c|c}
\hline Dado & Itens & $\mathbf{N}$ & $\mathbf{\%}$ \\
\hline \multirow{4}{*}{$\begin{array}{c}\text { Trabalho antes e } \\
\text { durante a pandemia }\end{array}$} & $\begin{array}{l}\text { Permaneceram no mesmo trabalho e desenvolvendo as } \\
\text { mesmas atividades, porém de forma remota (home } \\
\text { office). }\end{array}$ & 31 & 70,5 \\
\cline { 2 - 4 } & $\begin{array}{l}\text { Permaneceram no mesmo trabalho e desenvolvendo as } \\
\text { mesmas atividades, da mesma forma antes da pandemia. }\end{array}$ & 8 & 18,2 \\
\cline { 2 - 4 } & $\begin{array}{l}\text { Realizaram atividades diferentes das que fazia/executava } \\
\text { no trabalho. }\end{array}$ & 2 & 4,5 \\
\cline { 2 - 4 } & Situação diferente de trabalho durante a pandemia. & 3 & 6,8 \\
\hline \multirow{4}{*}{$\begin{array}{c}\text { Tempo diário de } \\
\text { trabalho }\end{array}$} & Até 6 horas & 4 & 9,1 \\
\cline { 2 - 4 } & Entre 6 e 8 horas & 14 & 31,8 \\
\cline { 2 - 4 } $\begin{array}{c}\text { Demanda de } \\
\text { trabalho antes e } \\
\text { durante a pandemia }\end{array}$ & Entre 8 e 12 horas & 17 & 38,6 \\
\cline { 2 - 4 } & Mais de 12 horas & 9 & 20,5 \\
\cline { 2 - 4 } & A demanda diminuiu na pandemia. & 6 & 13,6 \\
\hline
\end{tabular}

Fonte: Elaborada pelo autor

O trabalho é valorizado tanto pelo discurso social acerca da sua importância, que considera o trabalhador como um sujeito produtivo, quanto pelo retorno alcançado por essa dimensão, seja subjetiva ou material (LOSEKANN; MOURÃO, 2020). Durante o isolamento social, via home office, houve aumento da jornada devido à necessidade de um rápido e imediato ajuste para suavizar os impactos da pandemia nos diversos setores empregatícios. Uma das causas desse acréscimo, o medo de perder o posto de trabalho, 
Impactos da Pandemia de COVID-19 no Lazer e no Trabalho do Professor Universitário em Home Office

Vagner Miranda da Conceição

pode comprometer ainda mais a vida e o tempo que a preenche durante esse momento atípico (CLEMENTE; STOPPA, 2020). Para além, existe um desafio que é equilibrar a relação tempo e esforço no trabalho, ação subjetiva que é indiretamente acionada pela necessidade de responder ao seu superior ou entregar os produtos do seu labor (LOSEKANN; MOURÃO, 2020). No entanto, nesse momento que todos os tempos, funções e espaços sociais estão fundidos no lar, parece que todas as (sobre) cargas são potencializadas, exigindo mais ainda do professor.

Percebe-se que, indo para o home office, e com o aumento da demanda de trabalho, o tempo de dedicação e de produção no trabalho seguiu o mesmo caminho. Para 59,1\% dos professores o tempo de dedicação ao trabalho é de mais de 8 horas diárias, o que foge da realidade de um trabalhador, pois geralmente esse tempo de trabalho é de 6 ou 8 horas por dia. O professor não trabalha somente no horário de aula e dedica muito do seu tempo na preparação de aulas e atividades. Num contexto de pandemia parece ser esperado, mas não aceitável, o aumento dessa demanda, em especial no momento da coleta dos dados, início da "primeira onda", que exigiu do professorado (re) organização, realização e entrega das atividades laborais.

\section{O Tempo de Lazer Diminuiu e Trouxe Insatisfação}

Acerca do lazer dos professores antes e durante a pandemia, para 33 professores (75\%) o tempo para o lazer diminuiu. Sobre o nível de satisfação com o tempo de lazer durante a pandemia, numa escala de 1 a 5, onde 1 é nenhuma satisfação e 5 é satisfação total, $60,9 \%$ das respostas estão direcionadas à insatisfação. 
Impactos da Pandemia de COVID-19 no Lazer e no Trabalho do Professor Universitário em Home Office

Vagner Miranda da Conceição

Tabela 4:Frequência e Percentual Sobre Tempo e Satisfação com o Lazer

\begin{tabular}{c|l|c|c}
\hline \multicolumn{1}{c|}{ Dado } & Itens & $\mathbf{N}$ & $\mathbf{\%}$ \\
\hline \multirow{4}{*}{ Tempo para o lazer } & $\begin{array}{l}\text { Não tinham tempo para o lazer antes e continuam não } \\
\text { tendo durante a pandemia. }\end{array}$ & 2 & 4,5 \\
\cline { 2 - 4 } & O tempo de lazer é o mesmo de antes da pandemia & 7 & 15,9 \\
\cline { 2 - 4 } & O tempo de lazer aumentou & 2 & 4,5 \\
\cline { 2 - 4 } & O tempo de lazer diminuiu & 33 & 75,0 \\
\hline \multirow{4}{*}{$\begin{array}{c}\text { Nível de satisfação } \\
\text { com o lazer }\end{array}$} & 1 - Nenhuma satisfação & 10 & 22,7 \\
\cline { 2 - 4 } & 2 & 17 & 38,6 \\
\cline { 2 - 4 } & 4 & 9 & 20,5 \\
\cline { 2 - 4 } & 5-Satisfação total & 4 & 9,1 \\
\hline
\end{tabular}

Fonte: Elaborada pelo autor

Existe uma tendência em adultos de priorizar as obrigações em detrimento ao lazer, deslocando-o para o tempo disponível. O lazer é valorizado, mas as obrigações, em especial o trabalho, recebem um foco maior dessa fase da vida, devido à todas as demandas socioeconômicas de responsabilidade desses sujeitos para manter a si e os seus dependentes. O envolvimento com as atividades de lazer diminuiu durante a pandemia e o tempo diário foi preenchido, para além das atividades de home office, com atividades domésticas e cuidados com outras pessoas (MATOS; PINHEIRO; BAHIA, 2020).

Os espaços de lazer, local de encontro entre amigos e familiares, tiveram que ser fechados para conter o avanço do vírus, comprometendo percepções, sensações e emoções positivas oriundas do lazer vivido, não somente nesses espaços, mas amplamente propiciado pela experiência de lazer fora do lar. Silva et al. (2020) ressalta que o distanciamento não voluntário e o afastamento forçado para evitar contato e consequentes possíveis contágios tem gerado emoções negativas (ansiedade, depressão, indignação etc.) e diminuição das emoções positivas (felicidade, satisfação, prazer etc.).

A conjunção falta de tempo e de espaço, acúmulo de tarefas e aumento da demanda desperta emoções que impactam na satisfação dos sujeitos acerca da experiência vivida, de lazer ou não. Para além, a satisfação com essas práticas também é comprometida pelas limitadas trocas e contatos sociais, mas tal fato não deve ser 
Impactos da Pandemia de COVID-19 no Lazer e no Trabalho do Professor Universitário em Home Office

Vagner Miranda da Conceição

generalizado, pois a satisfação ainda pôde ser alcançada por algumas pessoas em tempo de isolamento social (SILVA et al., 2020; CASTILHO; RIBEIRO; UNGHERI, 2020).

\section{Práticas de Lazer Antes e Durante a Pandemia}

No lazer vivenciado antes da pandemia, destacam-se os interesses social, encontrar amigos e familiares fora de casa (79,5\%); artístico: assistir TV, séries, filmes em casa $(59,1 \%)$; turístico: viajar nos finais de semana ou feriados $(56,8 \%)$; e físicoesportivo: praticar atividades físicas e/ou esportivas em espaços privados $(54,5 \%)$ (TABELA 6). Os professores poderiam assinalar mais de uma opção e/ou inserir a prática realizada que não estivesse entre as opções de respostas.

Tabela 6: Frequência e Percentual das Práticas de Lazer por Interesse Cultural Antes da Pandemia de COVID-19

\begin{tabular}{|c|c|c|c|c|}
\hline Interesse cultural & Atividade de lazer & N1 & $\%$ & N2 \\
\hline \multirow{6}{*}{ Social } & Encontrava amigos e/ou familiares fora de casa & 35 & 79,5 & \multirow{6}{*}{92} \\
\hline & Frequentava bares e restaurantes & 32 & 72,7 & \\
\hline & Frequentava festas & 15 & 34,1 & \\
\hline & Namorava & 7 & 15,9 & \\
\hline & Outros jogos e brincadeiras & 2 & 4,5 & \\
\hline & Encontros virtuais com amigos & 1 & 2,3 & \\
\hline \multirow{5}{*}{ Artístico } & Assistia TV, séries, filmes em casa & 26 & 59,1 & \multirow{5}{*}{68} \\
\hline & Assistia filmes no cinema & 24 & 54,5 & \\
\hline & $\begin{array}{l}\text { Assistia peças de teatro ou dança em teatros ou unidades } \\
\text { do SESC ou SESI }\end{array}$ & 9 & 20,5 & \\
\hline & $\begin{array}{l}\text { Assistia a shows em casas de shows, teatros ou unidades } \\
\text { do SESC ou SESI }\end{array}$ & 7 & 15,9 & \\
\hline & Tocava algum instrumento musical & 2 & 4,5 & \\
\hline \multirow{4}{*}{ Turístico } & Viajava nos finais de semana ou feriados & 25 & 56,8 & \multirow{4}{*}{68} \\
\hline & Frequentava shoppings centers & 23 & 52,3 & \\
\hline & Fazia passeios ao ar livre com animais de estimação & 13 & 29,5 & \\
\hline & Fazia excursões em sítios ou cidades (passeios de um dia) & 7 & 15,9 & \\
\hline \multirow{3}{*}{ Físico-esportivo } & $\begin{array}{l}\text { Praticava atividades físicas e/ou esportivas em espaços } \\
\text { privados (academias, clubes, SESC, SESI etc.) }\end{array}$ & 24 & 54,5 & \multirow{3}{*}{42} \\
\hline & $\begin{array}{l}\text { Praticava atividades físicas e/ou esportivas em espaços } \\
\text { públicos (parques, praças, ruas etc.) }\end{array}$ & 15 & 34,1 & \\
\hline & Assistia esporte em estádios, centros esportivos ou clubes & 3 & 6,8 & \\
\hline \multirow{3}{*}{ Manual } & Cozinhava por prazer & 19 & 43,2 & \multirow{3}{*}{33} \\
\hline & Cuidava do jardim ou horta por prazer & 11 & 25,0 & \\
\hline & $\begin{array}{l}\text { Outros hobbies ligados a serviços manuais, artesanato, } \\
\text { montagem de ferramentas }\end{array}$ & 3 & 6,8 & \\
\hline \multirow{4}{*}{ Intelectual } & Fazia leituras (livros, jornais, revistas etc.) & 16 & 36,4 & \multirow{4}{*}{31} \\
\hline & $\begin{array}{l}\text { Visitava museus, centros culturais ou outros espaços } \\
\text { culturais }\end{array}$ & 7 & 15,9 & \\
\hline & $\begin{array}{l}\text { Fazia cursos (idiomas ou outros temas de interesse) } \\
\text { presencialmente }\end{array}$ & 7 & 15,9 & \\
\hline & Jogava jogos de tabuleiros com amigos ou familiares & 1 & 2,3 & \\
\hline
\end{tabular}


Impactos da Pandemia de COVID-19 no Lazer e no Trabalho do Professor Universitário em Home Office

Vagner Miranda da Conceição

\begin{tabular}{c|l|c|c|c}
\hline & (dama, xadrez etc.) & & \\
\hline \multirow{2}{*}{ Virtual } & Navegava na internet (sites e redes sociais etc.) & 22 & 50,0 & \multirow{2}{*}{25} \\
\cline { 2 - 4 } & Jogos de videogame e similares & 3 & 6,8 & \\
\hline \multirow{2}{*}{ Atividades de ócio } & $\begin{array}{l}\text { Ócio (não fazer nada, descanso, contemplação) em casa ou } \\
\text { outros espaços }\end{array}$ & 14 & 31,8 & \multirow{2}{*}{15} \\
\cline { 2 - 4 } & Pescaria & 1 & 2,3 & \\
\hline
\end{tabular}

Fonte: Elaborada pelo autor. N1 = frequência por atividade de lazer; N2 = frequência por interesse cultural

Durante a pandemia, a atividade de lazer mais frequente foi "Assistir TV, séries, filmes em casa", interesse artístico, no entanto, pela diversidade e quantitativo o interesse manual foi o mais expressivo (TABELA 7). A Tabela 8 apresenta as categorias para a mesma pergunta, mas que não se encaixam nos interesses culturais do lazer, que foram a base para as categorias de respostas. Os professores poderiam assinalar mais de uma opção e/ou inserir a prática realizada que não estivesse entre as opções de respostas.

\section{Tabela 7: Frequência e Percentual das Práticas de Lazer por Interesse Cultural Durante a Pandemia de COVID-19}

\begin{tabular}{|c|c|c|c|c|}
\hline Interesse cultural & Atividade de lazer & N1 & $\%$ & $\mathbf{N 2}$ \\
\hline \multirow{6}{*}{ Manual } & Cuidar de animais de estimação dentro de casa & 12 & 27,3 & \multirow{6}{*}{35} \\
\hline & Cozinhar por prazer & 10 & 22,7 & \\
\hline & Cuidar do jardim ou horta por prazer & 10 & 22,7 & \\
\hline & Fazer artesanatos & 1 & 2,3 & \\
\hline & Fazer objetos de decoração ou consertar móveis & 1 & 2,3 & \\
\hline & $\begin{array}{l}\text { Praticar algum tipo de artes plásticas (pinturas em } \\
\text { quadros, esculturas etc.) }\end{array}$ & 1 & 2,3 & \\
\hline \multirow{2}{*}{ Artístico } & Assistir TV, séries, filmes em casa & 27 & 61,4 & \multirow{2}{*}{29} \\
\hline & Tocar algum instrumento musical & 2 & 4,5 & \\
\hline \multirow{3}{*}{ Intelectual } & Fazer cursos online (idiomas ou outros temas de interesse) & 15 & 34,1 & \multirow{3}{*}{26} \\
\hline & Fazer leituras (livros, jornais, revistas etc.) & 8 & 18,2 & \\
\hline & $\begin{array}{l}\text { Jogar jogos de tabuleiros, cartas e afins (baralho, dama, } \\
\text { xadrez etc.) }\end{array}$ & 3 & 6,8 & \\
\hline \multirow{2}{*}{ Físico-esportivo } & Prática de atividades físicas e/ou esportivas em casa & 15 & 34,1 & \multirow{2}{*}{20} \\
\hline & Assistir esporte na TV ou internet & 5 & 11,4 & \\
\hline \multirow[t]{2}{*}{ Virtual } & $\begin{array}{l}\text { Navegar na internet (sites, lives de temas de interesse e } \\
\text { redes sociais etc.) }\end{array}$ & 14 & 31,8 & \multirow[t]{2}{*}{17} \\
\hline & Jogar videogame ou similares & 3 & 6,8 & \\
\hline \multirow[t]{2}{*}{ Social } & $\begin{array}{l}\text { Encontrar amigos e/ou familiares virtualmente (usando as } \\
\text { plataformas Skype, Google Meet, Zoom e afins) }\end{array}$ & 13 & 29,5 & \multirow[t]{2}{*}{15} \\
\hline & Namorar & 2 & 4,5 & \\
\hline & & & Total & 142 \\
\hline
\end{tabular}

Fonte: Elaborada pelo autor. N1 = frequência por atividade de lazer; N2 = frequência por interesse cultural 
Impactos da Pandemia de COVID-19 no Lazer e no Trabalho do Professor Universitário em Home Office

Vagner Miranda da Conceição

Tabela 8: Frequência e Percentual de Respostas Acerca das Práticas de Lazer Durante a Pandemia de COVID-19

\begin{tabular}{|c|c|c|c|c|}
\hline Interesse cultural & Atividade de lazer & N1 & $\%$ & $\mathbf{N 2}$ \\
\hline \multirow[b]{2}{*}{$\begin{array}{l}\text { Não tenho tido } \\
\text { tempo para o lazer }\end{array}$} & Aumentou o trabalho à distância & 13 & 29,5 & \multirow[b]{2}{*}{20} \\
\hline & $\begin{array}{l}\text { Aumentou o trabalho doméstico ou o cuidado com } \\
\text { familiares }\end{array}$ & 7 & 15,9 & \\
\hline \multirow[b]{2}{*}{ Atividades de ócio } & Ócio (não fazer nada, descanso, contemplação) em casa & 9 & 20,5 & \multirow[b]{2}{*}{17} \\
\hline & $\begin{array}{l}\text { "O tempo de lazer que tem sobrado é somente para o } \\
\text { descanso e dormir." }\end{array}$ & 8 & 18,2 & \\
\hline Lazer político & Bater panela para "Fora Bolsonaro!" & 1 & 2,3 & 1 \\
\hline & & & Total & 38 \\
\hline
\end{tabular}

Fonte: Elaborada pelo autor. N1 = frequência por atividade de lazer; N2 = frequência por interesse cultural

O lazer é um tempo e espaço para vivenciar atividades prazerosas (MELO, 2006) e promotoras de desenvolvimento pessoal e social (DUMAZEDIER, 1979). Para Gomes (2014) nem sempre é valorizado como deveria pelos sujeitos e pelas políticas públicas (MATOS; PINHEIRO; BAHIA, 2020). De encontro a essa (des) valorização, a pandemia tem desvelado a importância do lazer na vida humana trazendo à tona a sua necessidade e aproximação com a realidade (MATOS; PINHEIRO; BAHIA, 2020).

O isolamento social compromete a vivência de algumas atividades de lazer, em especial aquelas relacionadas a estar em lugares públicos ou privados junto com outras pessoas, tais como cinema, parque, shows etc. (MATOS; PINHEIRO; BAHIA, 2020). Para Gomes (2014), o lazer se efetiva num tempo/espaço social, sendo que o espaço é o lugar do encontro e de possíveis vínculos afetivos (MARCELLINO, 2012). Para os participantes dessa pesquisa, o interesse social do lazer foi o mais comprometido devido à pandemia e as suas medidas restritivas de distanciamento e isolamento social.

Como forma de suprir a necessidade de socialização, o uso de smartphones e de aplicativos se intensificaram nessa pandemia, aproximando as pessoas, que atualmente precisam estar separadas (CAVALCANTE, 2020). Contudo, tal usufruto pode acentuar as desigualdades sociais e de lazer, pois nem todas as pessoas possuem recursos financeiros para a compra e uso de um bom smartphone como forma de suprir a limitação ou ausência de espaços públicos de lazer (COUTO; REZENDE; MEDINA, 
Impactos da Pandemia de COVID-19 no Lazer e no Trabalho do Professor Universitário em Home Office

Vagner Miranda da Conceição

2020). Os dados dessa pesquisa não permitem afirmar essa aproximação com os smartphones, pois interesses de destaque na pandemia foram o manual e artístico, mas, caso ocorresse, infere-se que a barreira econômica não seria um limitante para o grupo pesquisado.

O lazer de interesse virtual torna-se opção em diversos estudos que investigaram o lazer durante a pandemia (CLEMENTE; STOPPA, 2020; SILVA et al., 2020; CASTILHO; RIBEIRO; UNGHERI, 2020), no entanto, para os professores dessa pesquisa, essas atividades praticamente continuam ocupando a mesma posição no ranking das atividades de interesse, sendo que durante a pandemia houve uma diminuição na frequência, em comparação com o antes da pandemia. Ademais, o isolamento e as limitações da pandemia elucidam a necessidade de (re) criação e expansão desse meio como forma de atenção e cuidado à saúde mental (FALCÃO; GOMES, 2020).

O acesso à internet diversifica e possibilita a interação social e a diversão e o desenvolvimento tecnológico trouxeram acesso a outros bens culturais, sendo que via internet, pode-se alcançar informações sobre outras formas (SCHWARTZ, 2003; RIBEIRO et al., 2020) e tempo-espaço de lazer (SCHWARTZ, 2003; SILVA et al., 2020). Certamente, os fatores tempo e demanda de trabalho influenciaram nas respostas dos professores dessa pesquisa acerca do interesse virtual, pois diferente de outros trabalhos publicados, não houve uma virtualização do lazer para o grupo pesquisado.

Assistir TV, séries, filmes em casa, antes e durante a pandemia, foi a atividade de lazer mais frequente do interesse artístico. Além dessa possibilidade, surge o streaming que facilita e populariza o consumo de séries, programas de TV etc. (MATOS; PINHEIRO; BAHIA, 2020). Cavalcante (2020) aponta que dentre os aplicativos mais baixados para celular durante a pandemia, estão os de serviço de 
Impactos da Pandemia de COVID-19 no Lazer e no Trabalho do Professor Universitário em Home Office

Vagner Miranda da Conceição

streaming, que impulsionaram o uso de diversas plataformas digitais (Netflix, Globoplay etc.) trazendo o lazer virtual e artístico para o centro da vida (CLEMENTE; STOPPA, 2020; FALCÃO; GOMES, 2020) e, possivelmente, da tela da TV, já que os professores estão em casa e a atividade de lazer mais frequente foi a que envolve a utilização desse aparelho.

Falcão e Gomes (2020) entendem que a utilização das plataformas virtuais são uma forma de resistir ao isolamento social e que o consumo dos produtos audiovisuais (filmes, séries, documentários e animações) pode e deve, como experiência de lazer promover a ampliação cultural dos sujeitos, pois para além da ocupação alienante do tempo, promove aprendizados. O desenvolvimento pessoal é uma das possibilidades no lazer e ressalta-se a necessidade dessa compreensão para que as experiências de lazer, sejam capazes de promover e estimular novos modos de ser, estar, analisar e se relacionar com a sociedade. A (trans) formação via entretenimento audiovisual pode estimular reflexões acerca do lazer e de diversas dimensões da vida conduzindo o sujeito a questionar o seu cotidiano (FALCÃO; GOMES, 2020).

Como novidade na pandemia, surgiram as lives, uma prática alentadora para aqueles que apreciavam os shows presenciais. Artistas brasileiros e internacionais, por iniciativas diversas, faziam apresentações via plataformas virtuais. As produções foram se aperfeiçoando e nos três primeiros meses de pandemia foram realizados "shows virtuais" que as pessoas podiam acompanhar de casa, trazendo uma nova forma de estar e de consumir no lazer (MATOS; PINHEIRO; BAHIA, 2020). Esses shows permitiram que pessoas que não tinham possibilidades financeiras pudessem ver e acompanhar alguns artistas, pois, na sua maioria, foram gratuitas (SILVA et al., 2020)

Cabe ressaltar que nem todas as pessoas possuem acesso de qualidade à internet e/ou competências e habilidades para utilizar as diversas ferramentas do ambiente 
Impactos da Pandemia de COVID-19 no Lazer e no Trabalho do Professor Universitário em Home Office

Vagner Miranda da Conceição

virtual para acompanhar as produções compartilhadas em plataformas digitais (CLEMENTE; STOPPA, 2020). As atividades online não substituíram aquilo que é inerente ao ser humano: a troca, o contato, o conviver, mas suavizaram as dores e as angústias oriundas da limitação do contato social (MATOS; PINHEIRO; BAHIA, 2020). E, nesse contexto da interação social, Silva et al. (2020) alertam que o uso de alguns meios de comunicação e de entretenimento virtuais deve ser feito com prudência e consciência, pois sem cuidado podem ser geradas frustrações (FRAGA; SILVA, 2010).

O interesse físico-esportivo, devido às restrições de espaço e aglomeração, sofreu adaptações. A pandemia trouxe um olhar voltado para si, para os do seu convívio e para o espaço casa, estimulando a criatividade e potencializando a busca por novas vivências de lazer.

Silva et al. (2020) relatam que a prática de exercícios e os seus benefícios é o que as pessoas sentem falta e não as academias, que não são serviços essenciais. A necessidade de realização de atividade física fez com que os professores adaptassem o exercício físico para o ambiente casa, que passa a ser o único espaço seguro para a vivência do lazer (SILVA et al., 2020), mas que pode ter limitações - espaço, materiais, orientação etc. - para a prática físico-esportiva (COUTO; REZENDE; MEDINA, 2020). Para a supervisão e manutenção do exercício físico, surge o profissional virtual, que via tecnologias desempenha a tarefa de manter a atividade física (RIBEIRO et al., 2020), desvelando um novo modo de relacionar tempo/espaço, engajamento com a atividade física e processo de virtualização das atividades cotidianas.

No grupo pesquisado, o engajamento com o exercício físico vai de 88,7\% para $31,8 \%$ - antes e durante a pandemia. A condição de isolamento social associada ao home office tende a aumentar o sedentarismo e/ou as consequências da inatividade física entre 
Impactos da Pandemia de COVID-19 no Lazer e no Trabalho do Professor Universitário em Home Office

Vagner Miranda da Conceição

as pessoas, pois são despendidas muitas horas diante do computador (BRANCACCIO et al., 2021), o que é o caso do professor universitário, pois seu trabalho - a aula demanda muito tempo de preparação. Para os sedentários de antes da pandemia, as medidas de isolamento podem ainda ser mais agravantes (SILVA et al., 2020), reafirmando a necessidade da busca e engajamento em atividades físicas em casa, ou não.

Os interesses manuais, que antes da pandemia apareciam como opção após os interesses social, artístico, turístico e físico-esportivo, durante a pandemia se torna a opção mais frequente pelo quantitativo de práticas. No entanto, ressalta-se que as outras práticas reduziram consideravelmente as suas frequências e os interesses manuais praticamente mantiveram a sua frequência. Mayor e Isayama (2017) elucidam que a pequena frequência dessas práticas de lazer pode estar relacionada a um contexto social que valoriza o trabalho e é pouco sensível às outras instâncias das experiências humanas.

A frequência das atividades manuais pode ter variado pouco e se mantido em relação aos interesses que precisam do espaço fora de casa para sua efetivação, pois geralmente são atividades realizadas no espaço doméstico, associado ao universo feminino (MAYOR; SILVA; LOPES, 2020) que, nessa pesquisa, em frequência, é mais expressiva. Ademais, as autoras apontam que o interesse manual tem uma frequência maior entre mulheres que trabalham, que pode ser o caso das professoras dessa pesquisa.

Dumazedier (1980) e Marcellino (2012) apresentam compreensões diferentes acerca do lazer relacionado aos interesses manuais. Para o primeiro, são semilazer por apresentar um fim utilitário, mas para o segundo, se enquadram como lazer por gerar prazer, aliviar tensões, por não ter um objetivo econômico. Para Silva et al. (2020), após 
Impactos da Pandemia de COVID-19 no Lazer e no Trabalho do Professor Universitário em Home Office

Vagner Miranda da Conceição

a compreensão da necessidade de reinventar as práticas de lazer, o lazer manual ganhou espaço e significado na vida das pessoas, muitas vezes sendo vivenciado em família, fortalecendo o vínculo afetivo, ganhando espaço entre as opções de lazer e trazendo novos aprendizados para a vida cotidiana no contexto de pandemia.

Nos interesses intelectuais, houve uma inversão de preferência entre fazer leituras (livros, jornais, revistas etc.), que antes da pandemia predominava nesse interesse, com o fazer cursos (idiomas ou outros temas de interesse) - antes da pandemia, presencial; durante, online. Assim como em Ribeiro et al. (2020), não foi especificado o tipo de leitura e de cursos, que dependendo da origem, poderia ser entendida como formação, obrigação, e nesse caso, não seria lazer.

Quanto aos cursos online, durante a pandemia, houve um boom de ofertas e divulgação de cursos e atividades de formação gratuitas, ou não. A realização de um curso de interesse, que antes poderia ter algum empecilho (logísticas de tempo, deslocamento, presencialidade e distância), agora, via ambiente virtual, pôde tornar-se realizável pela minimização e/ou excludência desses fatores limitantes. Infere-se a conjunção boom, tempo em casa e acesso constante a computador/internet como o potencializador dessas práticas para o tempo de lazer. Também foram ofertados cursos para qualificação e formação profissional, mas não são lazer, pois nesse caso o foco é a atuação profissional.

O interesse turístico, que antes da pandemia estava em segunda opção com o interesse artístico, durante a pandemia, se ausenta das escolhas dos professores. As vivências de lazer que sofreram os maiores impactos são aquelas dos espaços não domiciliares (MAYOR. SILVA; LOPES, 2020). Devido à necessidade de isolamento, viagens e passeios foram cancelados e adiados, impactando tanto os viajantes quanto as agências de viagens (CLEMENTE; STOPPA, 2020). 
Impactos da Pandemia de COVID-19 no Lazer e no Trabalho do Professor Universitário em Home Office

Vagner Miranda da Conceição

Tal iniciativa, é uma das principais para evitar o deslocamento do vírus pelo espaço, premissa para salvar vidas. O turismo presencial teve que ser reinventado e surgiram as opções do turismo online com visitas virtuais a museus (CLEMENTE; STOPPA, 2020). No entanto, do ponto de vista da experiência, de conhecer e vivenciar a localidade e a cultura do outro, as perdas são significativas para todos aqueles que estão com o deslocamento restrito ao lar e aos serviços essenciais (MAYOR. SILVA; LOPES, 2020). A mudança de espaço é essencial para a vivência do lazer turístico e os prejuízos advindos do isolamento e do distanciamento social comprometem a assimilação dos benefícios relacionados ao descanso, ao divertimento e ao desenvolvimento pessoal.

Há de se ressaltar a expressiva diferença entre os quantitativos totais de atividades de lazer antes (342) e durante (160) a pandemia. As medidas de isolamento certamente influenciaram nessa diferença, mas houve também um aumento das demandas domésticas, de atenção e cuidado com familiares e do próprio trabalho remoto, que se entrelaçaram no tempo livre, dificultando distinguir quando é trabalho ou não. Losekann e Mourão (2020) afirmam que o trabalho intenso, que divide e imbrica em outros espaços, pode diminuir o tempo para o lazer descanso, diversão ou desenvolvimento.

A maioria dos professores são mulheres, que possuem limitações e dificuldades para ter e/ou aproveitar o tempo de lazer devido à histórica, social e cultural - e machista - desigualdade de gênero, que resulta num acúmulo de tarefas (trabalhar, estudar, cuidar de filhos, casa, parceiro afetivo etc.) (MARQUES et al., 2020; MAYOR; SILVA; LOPES, 2020; RIBEIRO et al., 2020). Mesmo com avanços e diminuição do tempo acumulado, atualmente, as mulheres ainda são as maiores responsáveis pelas atividades domésticas (MAYOR; SILVA; LOPES, 2020). Para Falcão e Gomes (2020) 
Impactos da Pandemia de COVID-19 no Lazer e no Trabalho do Professor Universitário em Home Office

Vagner Miranda da Conceição

tal fato é uma coação social velada, resultado de um patriarcado machista que ainda perpetua as desigualdades de gênero, impactando diretamente nas vivências de lazer.

O tempo para as práticas de lazer também foi impactado pelas demandas de ajuste, aprendizado, organização e controle imediato do trabalho remoto (home office). Tal processo demanda tempo, consumindo aquele que poderia ser o momento de lazer dos professores (LOSEKANN; MOURÃO, 2020; RIBEIRO et al., 2020). Nessa lógica, parte do tempo de lazer tem sido usado para descansar, relaxar, dormir, para o ócio. Sobre a livre escolha no tempo disponível, a condição de ócio tem suma importância e há de ser considerado (RIBEIRO et al., 2020).

A escolha só é possível a partir das possibilidades e o processo de educação para e pelo lazer é primordial, pois promove a reflexão, desenvolve a autonomia e estimula a criticidade e a criatividade, indo de encontro a massificação das práticas (MARCELLINO, 2012). Ademais, possibilita também a vivência do ócio, de forma livre, sem a "culpa” por não estar trabalhando, produzindo ou entregando algo para a sociedade.

O lazer, que tem como um de seus pilares a liberdade, também é tempo de reivindicação política e de expressão das angústias, inquietudes e insatisfações sociais promovendo e estimulando mudanças em busca de uma nova ordem sociocultural (CLEMENTE; STOPPA, 2020). Um professor (P29), inseriu em "Outras atividades", como prática de lazer que não estava listada entre as opções de resposta, o "Bater panela para Fora Bolsonaro!". Tal fato merece destaque, pois o lazer é tempo de (trans) formação social, de reflexão e de crítica.

Atualmente, a sociedade brasileira está no centro de uma crise não somente sanitária, mas sociopolítica, que perpassa e abrange a saúde e a educação e que é potencializada pelo compartilhamento das fakenews e por ações que diminuem e 
Impactos da Pandemia de COVID-19 no Lazer e no Trabalho do Professor Universitário em Home Office

Vagner Miranda da Conceição

desvalorizam as políticas públicas e os direitos sociais, evidenciando o desamparo do governo Bolsonaro ao povo brasileiro (GOMES; ARAÚJO, 2020; LINS et al., 2020). Esse abandono reverbera na atuação do professor, pois as condições de saúde, trabalho e lazer são impactadas por toda essa inatividade.

O chefe de Estado brasileiro, num momento tão crítico como o da pandemia de COVID-19, não tem agido como tal. De forma oposta às recomendações da OMS e às atitudes de vários líderes mundiais, tem utilizado com um discurso anti ciência e, de encontro à todas as recomendações da OMS, cruzado o país sem máscara, provocando aglomerações, estimulando o uso de medicamentos sem comprovação científica e agido demasiadamente lento para a aquisição de vacinas. Para além, tem emitido declarações desrespeitosas e nada empáticas com as famílias das mais de $260^{3}$ mil vítimas e com todo o povo brasileiro que acredita na Ciência e precisa urgentemente de ação em pró da mesma, pois caso contrário, todos serão vítimas não só do vírus, mas também de um governo negacionista, corrupto, genocida e irresponsável.

Clemente e Stoppa (2020) apontaram as redes sociais como locais de participação no lazer e expressão de insatisfações com representantes políticos que não tem sido a favor da vida. No entanto, percebe-se que para além e de formas diversas, o "lazer manifestação" se faz presente nas carreatas, nos gritos dos oprimidos e indignados nas janelas e nas manifestações artísticas, em especial durante a pandemia e com a Educação brasileira que tem sido atingida por injustas (declar) ações.

\section{Lazer: O Que Mais Sente Falta e Aprendizado de Algo Novo}

Sobre as atividades de lazer durante a pandemia, os professores relataram que mais sentem falta de práticas relacionadas aos interesses sociais e físico-esportivos. De

\footnotetext{
${ }^{3}$ Dados extraídos em 16/03/2021.
} 
Impactos da Pandemia de COVID-19 no Lazer e no Trabalho do Professor Universitário em Home Office

Vagner Miranda da Conceição

forma menos expressiva, mas não menos importante, foram relatadas atividade relacionadas aos interesses turísticos, intelectual e, também, relacionadas ao ócio.

(TABELA 9). Para essa pergunta o participante poderia citar mais de uma atividade.

Tabela 9: Frequência e Percentual das Atividades de Lazer que Fizeram Falta Durante a Pandemia de COVID-19

\begin{tabular}{|c|c|c|c|c|}
\hline Interesse cultural & Atividade de lazer & N1 & $\%$ & $\mathbf{N 2}$ \\
\hline \multirow{7}{*}{ Social } & Encontrar amigos & 11 & 25 & \multirow{7}{*}{31} \\
\hline & Visitar familiares & 7 & 15,9 & \\
\hline & Ir a bares e restaurantes & 6 & 13,6 & \\
\hline & Receber amigos em casa & 3 & 6,8 & \\
\hline & Festas & 2 & 4,5 & \\
\hline & Churrasco & 1 & 2,3 & \\
\hline & Sair com o namorado & 1 & 2,3 & \\
\hline \multirow{6}{*}{ Físico-esportivo } & Ir à academia & 9 & 20,5 & \multirow{6}{*}{17} \\
\hline & Nadar & 3 & 6,8 & \\
\hline & Pedalar & 2 & 4,5 & \\
\hline & Exercitar na rua & 1 & 2,3 & \\
\hline & Jogar vôlei & 1 & 2,3 & \\
\hline & Fazer caminhada & 1 & 2,3 & \\
\hline \multirow{4}{*}{ Turístico } & Viajar & 4 & 9,1 & \multirow{4}{*}{7} \\
\hline & Passear & 1 & 2,3 & \\
\hline & Ir para sítio & 1 & 2,3 & \\
\hline & Passeio parque com meus animais de estimação & 1 & 2,3 & \\
\hline \multirow{2}{*}{ Intelectual } & Aula de canto & 1 & 2,3 & \multirow{2}{*}{2} \\
\hline & Aula de sapateado & 1 & 2,3 & \\
\hline Ócio & Pescaria & 1 & 2,3 & 1 \\
\hline
\end{tabular}

Fonte: Elaborada pelo autor. $\mathrm{N} 1$ = frequência por atividade de lazer; $\mathrm{N} 2$ = frequência por interesse cultural

A partir do momento que as rotinas de lazer foram transformadas pela pandemia, a relação tempo e espaço para essas práticas foram as mais comprometidas e estão fragilizadas (MAYOR; SILVA; LOPES, 2020). As barreiras para o lazer, para além do distanciamento e isolamento social se tornaram evidentes, a saber: limitação econômica, grau de instrução, tempo e espaço de lazer e de trabalho entrelaçado e em constante reordenação (MARCELLINO, 2012), acesso de qualidade e incapacidade para o uso crítico, criativo e otimizado da internet (CLEMENTE; STOPPA, 2020).

A limitação do encontro com outras pessoas e do acesso à alguns espaços de lazer auxiliam na compreensão de o interesse social do lazer ser o mais frequente. As limitadas atividades de lazer realizadas durante a pandemia pelos professores compreendem o lar e na sua maioria são práticas individuais e/ou que foram vivenciadas 
Impactos da Pandemia de COVID-19 no Lazer e no Trabalho do Professor Universitário em Home Office

Vagner Miranda da Conceição

com os entes que compartilham a reclusão durante a pandemia. Os professores relataram o desejo de encontrar com amigos e parentes em ambientes que permitem o contato e a interação social (festas, bar, churrasco e restaurante).

A sociabilidade pode ser potencializada a partir das experiências de lazer, tal como o engajamento e o prazer dessas práticas podem ser comprometidos pela falta de companhia (MATOS; PINHEIRO; BAHIA, 2020) e pela falta de tempo (MAYOR; ISAYAMA, 2017). Em tempos de isolamento social, os benefícios possíveis das experiências de lazer ficam prejudicados e aquém, se comparado a uma realidade que possibilita o estar com o outro em espaços diversos e sem restrições. Tal reflexão auxilia na compreensão do interesse social ser o mais saudoso entre os professores dessa pesquisa, por estudantes universitários (RIBEIRO et al., 2020) e para além, um dos mais comprometidos durante a pandemia de COVID-19.

Os professores também destacaram as atividades do interesse físico-esportivo como aquelas que também sentiram falta durante a pandemia. Muitos dos espaços para tais atividades são potenciais para a aglomeração e considerados como serviços não essenciais, os quais, após alguns decretos municipais e orientações da OMS, fossem fechados momentaneamente e/ou tivessem que paralisar as suas atividades.

Essa restrição estimulou a criatividade e fez com que alguns professores adaptassem os exercícios físicos para o ambiente casa, no entanto, Bezerra et al. (2020) apontam que existe uma correlação entre qualidade habitacional, renda e prática de atividades físicas durante a pandemia, o que pode ser uma das explicações para a baixa frequência do engajamento em exercícios físicos. A redução de aproximadamente $68 \%$, pode comprometer os benefícios relacionados a saúde da população, em especial a saúde mental, e o combate ao sedentarismo, sinalizando a necessidade de reflexão acerca da importância da realização de atividades físicas durante a pandemia. 
Impactos da Pandemia de COVID-19 no Lazer e no Trabalho do Professor Universitário em Home Office

Vagner Miranda da Conceição

Sobre o aprendizado de uma nova atividade de lazer durante a pandemia (TABELA 10$), 17(38,6 \%)$ professores se envolveram em novas atividades de lazer. Entre as novas práticas, destacaram os interesses: físico-esportivo (caminhada, exercício físico em casa e beachtennis) (6 - 35,3\%); e artístico (assistir lives/show online e vídeos no Youtube) $(4-23,5 \%)$.

Tabela 10: Frequência e Percentual das Novas Atividades de Lazer Aprendidas Durante a Pandemia de COVID-19

\begin{tabular}{|c|c|c|c|c|}
\hline Interesse cultural & Atividade de lazer & N1 & $\%$ & $\mathbf{N 2}$ \\
\hline \multirow{4}{*}{ Físico-esportivo } & Exercícios funcionais em casa & 3 & 6,8 & \multirow{4}{*}{6} \\
\hline & Fazer atividade física & 1 & 2,3 & \\
\hline & Caminhada & 1 & 2,3 & \\
\hline & Beach Tennis & 1 & 2,3 & \\
\hline \multirow{3}{*}{ Artístico } & Lives & 2 & 4,5 & \multirow{3}{*}{4} \\
\hline & Ver shows online & 1 & 2,3 & \\
\hline & Assistir grupos de música erudita e orquestras no Youtube & 1 & 2,3 & \\
\hline \multirow{3}{*}{ Intelectual } & Tarô & 1 & 2,3 & \multirow{3}{*}{3} \\
\hline & Aumentei o nível de leitura & 1 & 2,3 & \\
\hline & Criar aplicativos & 1 & 2,3 & \\
\hline \multirow{2}{*}{ Manual } & Cozinhar & 1 & 2,3 & \multirow{2}{*}{2} \\
\hline & Artesanato & 1 & 2,3 & \\
\hline Virtual & Dançar Tiktok com minha filha & 1 & 2,3 & 1 \\
\hline Ócio & Silenciar & 1 & 2,3 & 1 \\
\hline
\end{tabular}

Fonte: Elaborada pelo autor. $\mathrm{N} 1=$ frequência por atividade de lazer; N2 = frequência por interesse cultural

O anseio pela atividade física, seja para iniciar ou manter o exercício físico, foi o item de maior frequência nas respostas. O componente arte, que ajudou a preencher com qualidade o tempo de lazer, seja pelas lives ou pelos shows online/Youtube e o aprendizado de novas habilidades também foram relevantes. Por fim, o desejo de algo novo mostrou-se diverso em atividades de prazer, ócio e de desenvolvimento pessoal, demonstrando a importância dessas práticas.

\section{Importância e Necessidade do Lazer}

Somente um professor $(2,3 \%)$ disse que o lazer não é importante durante a pandemia, justificando sua resposta com "Porquê não tenho tempo para ele" (P8). Numa escala de 1 a 5 , onde 1 é pouco importante e 5 é muito importante, os professores 
Impactos da Pandemia de COVID-19 no Lazer e no Trabalho do Professor Universitário em Home Office

Vagner Miranda da Conceição

assinalaram os seguintes itens: 3) 5 (11,6\%); 4) 12 (27,9\%); e 5) $26(60,5 \%)$. Sobre a importância do lazer, as justificativas dos professores variaram entre: O lazer relaxa, descansa e alivia o estresse $(17-39,5 \%)$; O lazer distrai e diverte $(8-18,6 \%)$; mas também com argumentos sobre prazer, felicidade, equilíbrio, motivação para a vida, saúde, entre outros. Todos os professores (100\%) entendem o lazer como necessário durante a pandemia e a compreensão sobre a necessidade do lazer ou se manteve (25 $56,8 \%)$ ou mudou para necessário $(6-13,6 \%)$ ou para mais necessário $(13-29,6 \%)$. Nenhum professor assinalou os itens que referiam ao lazer não ser necessário e/ou ser menos necessário do que antes da pandemia (TABELA 11).

Tabela 11: Importância e Necessidade do Lazer e Durante a Pandemia de COVID19

\begin{tabular}{|c|c|c|c|}
\hline Dado & Itens & $\mathbf{N}$ & $\%$ \\
\hline \multirow{2}{*}{$\begin{array}{c}\text { O lazer é } \\
\text { importante? }\end{array}$} & Sim & 43 & $\mathbf{9 7 , 7}$ \\
\hline & Não & 1 & 2,3 \\
\hline \multirow{5}{*}{$\begin{array}{c}\text { Nível de } \\
\text { importância do } \\
\text { lazer }\end{array}$} & 1 - Pouco importante & 0 & $\mathbf{0}$ \\
\hline & 2 & 0 & $\mathbf{0}$ \\
\hline & 3 & 5 & 11,6 \\
\hline & 4 & 12 & 27,9 \\
\hline & 5 - Muito importante & 26 & 60,5 \\
\hline \multirow{5}{*}{$\begin{array}{l}\text { Justificativas de } \\
\text { importância: }\end{array}$} & Relaxa, descansa e alivia o estresse & 17 & 39,5 \\
\hline & Distrai e diverte & 8 & 18,6 \\
\hline & Gera prazer e felicidade & 6 & 14 \\
\hline & É equilíbrio e traz motivação para a vida & 6 & 14 \\
\hline & É saúde & 6 & 14 \\
\hline \multirow{4}{*}{ O lazer... } & É momento de interação com outras pessoas & 5 & 11,6 \\
\hline & É parte essencial da vida & 4 & $\mathbf{9 , 3}$ \\
\hline & Permite a liberdade & 2 & 5 \\
\hline & Possibilita desenvolvimento pessoal & 1 & 2,3 \\
\hline \multirow{2}{*}{$\begin{array}{c}\text { O lazer é } \\
\text { necessário? }\end{array}$} & Sim & 44 & 100 \\
\hline & Não & 0 & $\mathbf{0}$ \\
\hline \multirow{3}{*}{$\begin{array}{l}\text { Compreensão sobre } \\
\text { a necessidade do } \\
\text { lazer durante a } \\
\text { pandemia }\end{array}$} & Não mudou e continua a mesma de antes da pandemia. & 25 & 56,8 \\
\hline & Mudou e agora entende que o lazer é necessário. & 6 & 13,6 \\
\hline & $\begin{array}{l}\text { Mudou e agora entende que o lazer é mais necessário do } \\
\text { que antes da pandemia. }\end{array}$ & 13 & 29,6 \\
\hline
\end{tabular}

Fonte: Elaborada pelo autor

Viver um processo de quarentena e distanciamento social não é uma experiência agradável, pois exige a privação da liberdade e a separação de familiares e amigos, gerando insegurança em relação ao trabalho e podendo perturbar a dinâmica e a rotina de vida (BRANCACCIO et al., 2021). As manifestações sociais e as configurações de 
Impactos da Pandemia de COVID-19 no Lazer e no Trabalho do Professor Universitário em Home Office

Vagner Miranda da Conceição

vida foram ressignificadas tornando relevante e desafiador a compreensão acerca da percepção da importância e da necessidade lazer - direito social e experiência humana (trans) formadora - no contexto de pandemia (MATOS; PINHEIRO; BAHIA, 2020).

Para os professores, o lazer é altamente importante, pois relaxa, descansa, alivia o estresse, distrai e diverte e, durante a pandemia, se tornou ainda mais necessário. Tal compreensão pode ser devido à conjunção entre alta demanda de trabalho, diminuição do tempo de lazer e de alguns fatores positivos associados a essa prática e que podem influenciar na vida como um todo.

Durante a pandemia, as demandas intensas - mais tempo de dedicação ao trabalho, rápida adaptação às novas tecnologias e cobrança dos gestores - concomitante às incertezas do momento atual - quantidade insuficiente de vacinas, atuação governamental duvidosa, falta de controle da pandemia, medo da morte e do avanço do vírus etc. - podem desencadear sintomas de ansiedade e aumentar os níveis de estresse, o que pode ser um fator complicador para a vivência do tempo de lazer (MATOS; PINHEIRO; BAHIA, 2020; CLEMENTE; STOPPA, 2020; LOSEKANN; MOURÃO, 2020). Tais complicadores podem comprometer sentimentos, sensações e percepções positivas (prazer, felicidade, equilíbrio, motivação etc.) em relação às possíveis dinâmicas relacionais de ocupação de tempo e espaço.

As experiências de lazer podem proporcionar benefícios diversos, dentre eles a promoção e a manutenção da saúde (BATISTA; RIBEIRO; JUNIOR, 2012; RIBEIRO et al., 2020). Fiocruz (2020) sugere como estratégia de cuidado psíquico:

\footnotetext{
Investir em exercícios e ações que auxiliem na redução do nível de estresse agudo (meditação, leitura, exercícios de respiração, entre outros mecanismos que auxiliem a situar o pensamento no momento presente, bem como estimular a retomada de experiências e habilidades usadas em tempos difíceis do passado para gerenciar emoções durante a epidemia);

Manter ativa a rede socioafetiva, estabelecendo contato, mesmo que virtual, com familiares, amigos e colegas (FIOCRUZ, 2020, p.4-5).
} 
Impactos da Pandemia de COVID-19 no Lazer e no Trabalho do Professor Universitário em Home Office

Vagner Miranda da Conceição

O isolamento social pode impactar negativamente a saúde como um todo, mas a saúde mental merece destaque, pois todas as incertezas e angústias desse momento podem gerar estresse, ansiedade, depressão e outras disfunções psíquicas (RIBEIRO et al., 2020), podendo extrapolar e superar em número os problemas oriundos da COVID19 (SHIGEMURA et al., 2020). No contexto laboral, Losekann e Mourão (2020) apontam que o trabalho com metas respeitosas e alcançáveis é um dos caminhos para a preservação da saúde mental e consequente sucesso do home office. Fato é que todo esse ajuste a nova realidade de pandemia pode gerar incômodos e reações adversas se não houver um equilíbrio entre os tempos de trabalho e de não-trabalho, incluindo o tempo de lazer, que, dentre as suas possibilidades, é um amenizador de para o estresse.

As vivências de lazer são fortemente recomendadas nesse momento de pandemia, pois estão também associadas ao relaxamento, diversão e bem-estar indo de encontro às situações de estresse, proporcionando um momento de desligar-se das angústias e das tarefas obrigatórias, que tem ocupado tempo e demandado esforços extras para a realização da tarefa de ensinar. Mayor; Silva e Lopes (2020) relatam que as atividades que envolvem a sociabilidade, que foram limitadas na pandemia e são saudosas para os professores dessa pesquisa, tais como atividade física em ambiente aberto, são indicadas nesse momento em que a instabilidade psicológica é usual. Na busca pelo relaxamento, Cavalcante (2020) aponta que aplicativos relacionados a meditação podem auxiliar nesse momento e estão no ranking dos mais baixados durante a pandemia.

O lazer traz prazer e esse é, para alguns autores, um traço característico das atividades de lazer. Outras características são importantes, tais como a diversão/distração, que nos permite o desfocar do obrigatório para aquilo que gera bemestar e felicidade. As sensações e as emoções possíveis a partir do lazer ajudam a 
Impactos da Pandemia de COVID-19 no Lazer e no Trabalho do Professor Universitário em Home Office

Vagner Miranda da Conceição

efetivar, via elemento lúdico, o desenvolvimento pessoal e social, compreensão necessária e resultado almejado por todos aqueles que se debruçam nos Estudos do Lazer.

É necessário avançar na compreensão e nas vivências do lazer, assimilando tais atividades como práticas (trans) formadoras, promotoras e potencializadoras da mudança e do aprendizado humano que transporta os sujeitos dos níveis de passividade e conformismo para estados de reflexão e exercício real do conhecimento e da cidadania, que são instrumentos de entrada, permanência, embate e construção de novos modos sociais e políticos de ser e estar (MARCELLINO, 2012). A compreensão do lazer como desenvolvimento pessoal pode ser percebida nas práticas ressignificadas e descritas pelos professores como novas atividades de lazer aprendidas no período da pandemia, que trouxe novos valores e significados para esse momento e para o tempo de lazer, tanto pelo espaço quanto pelas relações que são e tem sido construídas nessas experiências (SILVA et al., 2020).

No entanto, o lazer ainda é entendido como válvula de escape, que ajuda a população a suportar as mazelas e as injustiças sociais (MARCELLINO, 2010), que parecem ter se unido e potencializado na atual crise sanitária. Clemente e Stoppa (2020) apontam que é necessário o desenvolvimento de uma sociedade inclusiva, justa e responsável e, para tal, são necessárias políticas públicas que promovam a participação social crítica, criativa e responsável. Mayor, Silva e Lopes (2020), ao dissertar sobre a democratização do lazer, ressaltam sobre a importância do amplo acesso às diversas atividades de lazer, seja em casa ou numa viagem, mas que para tal, durante a pandemia, é necessário o respeito às medidas de isolamento social, para que futuramente, professores e toda a população possam ter acesso amplo e universal ao lazer. 
Impactos da Pandemia de COVID-19 no Lazer e no Trabalho do Professor Universitário em Home Office

Vagner Miranda da Conceição

\section{Considerações Finais}

De antemão e tal como Mayor; Silva e Lopes (2020), essa é uma reflexão ainda sem conclusões, pois no momento de finalização desse trabalho, a situação pandêmica ainda está em processo, por sinal de forma mais devastadora que no seu início em março de 2020, impactando toda a dinâmica relacional e profissional do professor universitário e de toda a sociedade.

Essa pesquisa mostrou que a pandemia de COVID-19 tem reestruturado todas as formas possíveis de ser e estar, em especial, as vivências e as experiências de lazer do professor universitário, que para além da dimensão espaço, foram comprometidas pelo imbricamento das expressões do tempo em um único ambiente: o lar. As demandas laborais concomitantes às obrigações domésticas e familiares comprometeram o lazer do professor.

As atividades de lazer foram alteradas e reconstruídas para esse novo tempo, pois o lazer é um amenizador, um confortante para essa situação. O encontro e o contato com o outro foi ressignificado para o olhar para si e para o contexto dentro de casa, demostrando também que a arte, nas suas diversas expressões, e o corpo em movimento, itens por vezes deixados de lado antes da pandemia, são agora essenciais para a manutenção da saúde e da qualidade de vida.

O lazer vivenciado durante da pandemia sofre limitações e as barreiras à essas práticas tornam-se mais expressivas e evidentes. Quando associadas ao gênero e a escolaridade, percebe-se que alguns complicadores ainda se fazem presentes, tal como o acúmulo de tarefas pelas mulheres e a possibilidade de acesso e informação ao lazer. A diminuição e a ausência do lazer trazem, por um lado, insatisfação, mas por outro, a reconstrução do tempo, do espaço e das práticas, demonstrando a importância a necessidade do lazer para os professores universitários. 
Impactos da Pandemia de COVID-19 no Lazer e no Trabalho do Professor Universitário em Home Office

Vagner Miranda da Conceição

Essa pesquisa, realizada durante a pandemia, foi facilitada pelo contexto online de compartilhamento do questionário, trazendo, compreendendo e fortalecendo as plataformas virtuais como importantes ferramentas na coleta de dados. Alguns itens e questões, mesmo com análise anterior, podem ser melhorados e detalhados para uma futura coleta. $\mathrm{O}$ viés de seleção, pela amostra por conveniência, é um limitador. Por fim, por ser uma coleta de um determinado grupo social e num momento social específico, não é possível generalizar as reflexões realizadas, mas esses olhares podem trazer contribuições para novas e essenciais pesquisas no campo dos Estudos do Lazer.

\section{REFERÊNCIAS}

BATISTA, J.; RIBEIRO, O. C. F.; JUNIOR, P. N. Lazer e promoção de saúde: uma aproximação conveniente. Licere, Belo Horizonte: v.15, n. 2, p1-16, jun. 2012. DOI: https://doi.org/10.35699/1981-3171.2012.729

BARDIN, Laurence. Análise de conteúdo. São Paulo: Edições 70, 2011. 279p.

BEZERRA, A. C. V. et al. Fatores associados ao comportamento da população durante o isolamento social na pandemia de COVID-19. Ciência \& Saúde coletiva. v. 25, suppl.1, p. 2411-2421, 2020.

BRANCACCIO, M. et al. Effects of the COVID-19 pandemic on job activity, dietary behaviours and physical activity habits of university population of Naples, Italy. International Journal of Environmental Research Public and Health 2021, 18, 1502 .

CALlEGARI-JACQUES, S. M. Bioestatística: princípios e aplicação. São Paulo: Artmed, 2004.

CAMARGO, L. O. L. O que é lazer? São Paulo: Brasiliense, 1992.

CASTILHO, C. T.; RIBEIRO, S. P.; UNGHERI, B. O. Distanciamento social e tempo livre: paradoxos vivenciados por estudantes da universidade estadual de minas gerais no âmbito do lazer. Licere, Belo Horizonte, v. 23, n. 3, set/2020. DOI: http://doi.org/10.35699/2447-6218.2020.25216.

CAVAlCANTE, F. R. Aplicativos para Smartphones que Possibilitam o Lazer em Tempos de Lockdown. Licere, Belo Horizonte, v.23, n.3, set/2020. DOI: http://doi.org/10.35699/2447-6218.2020.25449. 
CLEMENTE, A. C. F.; STOPPA, E. A. Lazer Doméstico em Tempos de Pandemia da Covid-19. Licere, Belo Horizonte, v.23, n.3, set/2020. DOI: http://doi.org/10.35699/2447-6218.2020.25524.

CONCEIÇÃO, V. M. Lazer, dança e educação física escolar. 2018. 313 f. Tese (Doutorado) - Escola de Educação Física, Fisioterapia e Terapia Ocupacional, Universidade Federal de Minas Gerais, Belo Horizonte, 2018.

CORONAVÍRUS SECRETARIA DE ESTADO DE SAÚDE DE MINAS GERAIS (SESMG). Entenda a importância do distanciamento social. Disponível em: http://bit.ly/30LWizP. Acesso em: 05/03/21.

COSTA, B. R. L. Bola de neve virtual: $\mathrm{O}$ uso das redes sociais virtuais no processo de coleta de dados de uma pesquisa científica. Revista Interdisciplinar de Gestão Social, v. 7, n. 1, p. 15-37, 2018.

COUTO, A. C. P.; REZENDE, F. H. F.; MEDINA, A. C. R. Os impactos causados pelos decretos da Prefeitura de Belo Horizonte no lazer da população. Licere, Belo Horizonte, v.23, n.3, set/2020. DOI: http://doi.org/10.35699/2447-6218.2020.25421.

DUMAZEDIER, J. Sociologia empírica do lazer. São Paulo: Perspectiva, 1979.

Valores e conteúdos culturais do lazer. São Paulo: Sesc, 1980.

ESCALANTE, E.; GOLDEN, R., L.; MASON, D. J. Social Isolation and Loneliness: Imperatives for Health Care in a Post-COVID World. JAMA, v. 325n. , p. 520-521, 2021.

FALCÃO, D.; GOMES, C. L. Estratégia e Táticas do Projeto "Cine Luce" no Contexto Pandêmico da Covid-19: o lazer em foco. Licere, Belo Horizonte, v.23, n.3, set/2020. DOI: http://doi.org/10.35699/2447-6218.2020.25079.

FRAGA, E. A. M.; SILVA, C. L. Comunidades virtuais de internet: atualização do debate sobre lazer. Licere, v. 13, n.4, p.1-20, 2010. DOI: http://doi.org/10.35699/19813171.2010.791.

FUNDAÇÃO OSWALDO CRUZ (FIOCRUZ). Saúde mental e atenção psicossocial na pandemia de Covid-2019: a quarentena na Covid- 2019, orientações e estratégias de cuidado, 2020. Disponível em: http://bit.ly/3tkWVN6. Acesso em: 07 mar. 2021.

FURCERI, D.; LOUNGANI, P.; OSTRY, J. D. Como as pandemias deixam os pobres mais pobres. Fundo Monetário Internacional (FMI), 2020. Disponível em: https://bit.ly/3s3BrUV. Acesso em: 10 mar. 21.

GOMES, C. L. Lazer: necessidade humana e dimensão da cultura. Revista Brasileira de Estudos do Lazer. Belo Horizonte, v. 1, n.1, p.3-20, jan./abr. 2014.

GOMES, V. L. A.; ARAÚJO, A. C. ORICON-LINE: temas e perspectivas em debate para pensar o lazer em tempos pós-pandemia. Licere, Belo Horizonte, v.23, n.3, set/2020. DOI: http://doi.org/10.35699/2447-6218.2020.25436. 
GONDIM, S. M. G. Grupos Focais como técnica de investigação qualitativa: desafios metodológicos. Paidéia, v. 12, n. 24, p. 149-161, 2003.

INSTITUTO BRASILEIRO DE GEOGRAFIA E ESTATÍSTICA (IBGE). Censo Demográfico 2010. Disponível em: http://bit.ly/3uq2RV2. Acesso em: 02 mar. 21.

LINS, C. F. M. et al. Ócio, lazer e tempo livre das velhices em quarentena: perspectivas psicossociais de um estudo brasileiro. Licere, Belo Horizonte, v.23, n.3, set/2020. DOI: http://doi.org/10.35699/2447-6218.2020.25446.

LOSEKANN, R. G. C. B.; MOURÃO, H. C. Desafios do teletrabalho na pandemia COVID-19: quando o home vira office. Caderno de Administração, Maringá, v. 28, Ed. Esp., jun./2020. Disponível em: http://bit.ly/2P19gHy. Acesso em: 08 mar. 2021.

MARCELLINO, N. C. Lazer e cultura: algumas aproximações. In: (org.) Lazer e cultura. Campinas: Alínea, 2007. p.9-30.

Lazer e educação. Campinas: Papirus, 2010.

2012.

Estudos do lazer: uma introdução. 5. ed. rev. Campinas: Autores Associados,

MARQUES, E. S. et al. A violência contra mulheres, crianças e adolescentes em tempos de pandemia pela COVID-19: panorama, motivações e formas de enfrentamento. Cadernos de Saúde Pública, v. 36. 30 de abr. 2020.

MATOS, L. S.; PINHEIRO, W. C.; BAHIA, M. C. Vivências do Lazer para Discentes do Curso de Educação Física da Universidade Federal do Pará no Contexto de Pandemia da Covid - 19. Licere, Belo Horizonte, v.23, n.3, set/2020. DOI: http://doi.org/10.35699/2447-6218.2020.25433.

SOUTTOMAYOR, S.; ISAYAMA, H. F. O lazer do brasileiro: sexo, estado civil e escolaridade. In: ISAYAMA, H. F.; STOPPA, E. Lazer no Brasil: representações e concretizações das vivências cotidianas. Campinas: Autores Associados, 2017.

.; SILVA, M. de S.; LOPES, C. G. Perspectivas sobre o lazer das mulheres com a pandemia do novo coronavírus: reflexões a partir dos dados da pesquisa "o lazer no Brasil - representações e concretizações das vivências cotidianas". Licere, Belo Horizonte, v.23, n.3, set/2020. DOI: http://doi.org/10.35699/2447-6218.2020.25363.

MELO, V. A. A animação cultural: conceitos e propostas. Campinas: Papirus, 2006.

MONTENEGRO, G. M.; QUEIROZ, B. S.; DIAS, M. C. Lazer em tempos de distanciamento social: impactos da pandemia de covid-19 nas atividades de lazer de universitários na cidade de Macapá (AP). Licere, Belo Horizonte, v.23, n.3, set/2020. DOI: http://doi.org/10.35699/2447-6218.2020.24785.

ORGANIZAÇÃO PAN-AMERICANA DE SAÚDE (OPAS). OMS afirma que COVID-19 é agora caracterizada como pandemia. 11 de mar. 2020. Disponível em: https://bit.ly/2NklLx9. Acesso em: 07 mar. 2021. 
PEDRÃO, C. C.; UVINHA, R. R. O lazer do brasileiro: discussão dos dados coletados em escolaridade, renda, classes sociais e cor/raça. In: ISAYAMA, H. F.; STOPPA, E. Lazer no Brasil: representações e concretizações das vivências cotidianas. Campinas: Autores Associados, 2017.

RIBEIRO, O. C. F. et al. Os Impactos da Pandemia da Covid-19 no Lazer de Adultos e Idosos. Licere, Belo Horizonte, v.23, n.3, set/2020. DOI: http://doi.org/10.35699/24476218.2020.25456.

SCHWARTZ, G. M. O conteúdo virtual do lazer: contemporizando Dumazedier. Licere, Belo Horizonte, v. 6, n.2, p.23-32, 2003.

SHIGEMURA, J. et al. Public responses to the novel 2019 coronavirus (2019-nCov) in Japan: mental health consequences and target populations. Psychiatry Clinical Neurosciences, 2020.

SILVA, C. L. et al. Os dias entre o teto e o chão da casa: lazer e práticas corporais no contexto brasileiro em tempos da COVID-19. Licere, Belo Horizonte, v. 23, n.3, set/2020. DOI: http://doi.org/10.35699/2447-6218.2020.25111.

STOPPA, E. A.; ISAYAMA, H. F. (org.). Lazer no Brasil: representações e concretizações das vivências cotidianas. Campinas: autores associados, 2017.

WORLD HEALTH ORGANIZATION (WHO). COVID-19. Disponível em: https://www.who.int/covid-19. Acesso em: 05 mar. 2021.

\section{Endereço do Autor:}

Vagner Miranda da Conceição

Endereço eletrônico: eefvagner@hotmail.com 